\title{
RANCANG BANGUN PROTOTYPE HYDRO TURBINE JENIS CROSS-FLOW UNTUK PERKOTAAN
}

\author{
Andrianus, Steven Darmawan dan Abrar Riza \\ Program Studi Teknik Mesin, Fakultas Teknik, Universitas Tarumanagara \\ e-mail: andrianus789@gmail.com
}

\begin{abstract}
The problem of fossil fuel crisis, both petroleum and coal, and the phenomenon of climate change due to global warming, trigger the use of renewable energy that can overcome these problems. Cross-flow water turbine is one of the machine that can be used to produce small scale electric energy in small scope. This turbine can be used in urban areas to assist industrial activities and their usefulness in daily life. The use of the right materials and strong construction can produce a good shape so that this water turbine is not only make efficient energy but also efficient and ergonomic in its use. This study is conducted theoretically to a cross-flow turbine which assumed to operate at 10m water height with 1.4 $\mathrm{L} / \mathrm{s}$, outer diameter $150 \mathrm{~mm}$ and $75 \mathrm{~mm}$ thickness. The turbine consist of 15 blades with angle of attack of the blades is $30^{\circ}$. The results show that the turbine generate 119 Watt
\end{abstract}

Keywords: machine, cross-flow water turbine.

\section{PENDAHULUAN}

Pada saat ini telah banyak energi alternatif yang dibuat untuk menghasilkan energi listrik dari sumber yang lebih murah dan tersedia dalam jumlah besar guna memenuhi kebutuhan manusia akan listrik. Hal ini untuk menghindari manusia dari ketergantungan penggunaan energi dari sumber daya alam yang tidak dapat diperbaharui seperti minyak bumi, gas alam, dan batu bara. Pada tahun 2012, rasio elektrifikasi di Indonesia baru sebesar 71\%. Yang artinya masih 29\% dari rakyat Indonesia yang belum memiliki akses listrik. Seiring dengan kebutuhan masyarakat yang meningkat dan kemampuan pemerintah dalam menghasilkan listrik terbatas menyebabkan semua pihak dan semua sektor dipacu untuk berkontribusi dalam upaya penyediaan bahan baku energi [1].

Salah satu sumber energi alternatif tersebut bisa berasal dari air yang dipergunakan untuk pembangkit listrik tenaga air (PLTA) dengan sistem-sistem dan peralatan tertentu untuk menghasilkan energi dalam jumlah besar dengan biaya yang rendah dan mempunyai dampak lingkungan yang minimal. Turbin air jenis cross-flow merupakan salah satu penggerak mula (prime mover) dengan desain sederhana, dapat self-cleaning, berbiaya rendah, dengan efisiensi yang cukup tinggi sehingga juga prospektif untuk terus dikembangkan sebagai komponen dari sistem energi terbarukan [2-5]. Penggunaan turbin air ini dapat menghasilkan sebuah energi listrik yang sangat penting dalam kehidupan masyarakat sehari-hari karena selain bermanfaat untuk penerangan juga dapat digunakan untuk kegiatan produksi yang dapat menunjang ekonomi rakyat dimana kegunaannya antara lain dapat menghidupkan pompa, pemanas/pendingin, alat penggiling, alat pemotong, alat pemipil dan berbagai keperluan lainnya [6-7].

Namun, aplikasi turbin cross-flow saat ini identik dengan sumber energi potensial air dengan tinggi tekan dan laju alir yang relatif besar sehingga memerlukan lokasi yang terbatas dan sulit ditemukan di perkotaan. Berdasarkan kelebihan-kelebihan yang dimiliki, penggunaan turbin crossflow pada daerah perkotaan dengan sumber air pada parit besar memiliki potensi yang besar untuk dikembangan. Pengkondisian aliran air antara lain dapat dilakukan penggunaan pompa berskala kecil untuk mensimulasikan aliran air pada parit. Maka penelitian ini bertujuan untuk menghasilkan perancangan turbin air jenis cross-flow untuk dapat diaplikasikan pada daerah perkotaan guna menunjang produksi sehingga dapat meningkatkan perekonomian negara, mengurangi penggunaan sumber daya alam yang sulit diperbaharui dan menggantikannya dengan sumber daya alam yang mudah diperbaharui untuk menghemat biaya dan mendukung gerakan ramah lingkungan. 


\section{METODOLOGI PENELITIAN}

Metode penelitian yang digunakan pada rancang-bangun mesin turbin air adalah menggunakan metode teoritis dan eksperimen. Hasil perancangan terhadap sistem turbin cross-flow dimanufaktur dan diuji. Perancangan terhadap turbin cross-flow dilakukan berdasarkan kriteria perancangan sebagai berikut:

- $\quad$ Head turbin $=10 \mathrm{~m}$

- Debit air $=1,4 \mathrm{~L} / \mathrm{s}$

- Diameter luar runner $150 \mathrm{~mm}$ dan tinggi $75 \mathrm{~mm}$

- Sudut serang turbin yaitu $30^{\circ}$ [8]

- Jumlah sudu turbin 15 buah

- Material turbin Aluminium 6061

Di mana penelitian tindakkan bertujuan untuk pengembangan pemanfaatan energi secara maksimal dengan melakukan tindakan dan penelitian di lapangan secara langsung. Proses dilakukan dengan melakukan desain pada software dan diwujudkan dalam bentuk barang jadi.
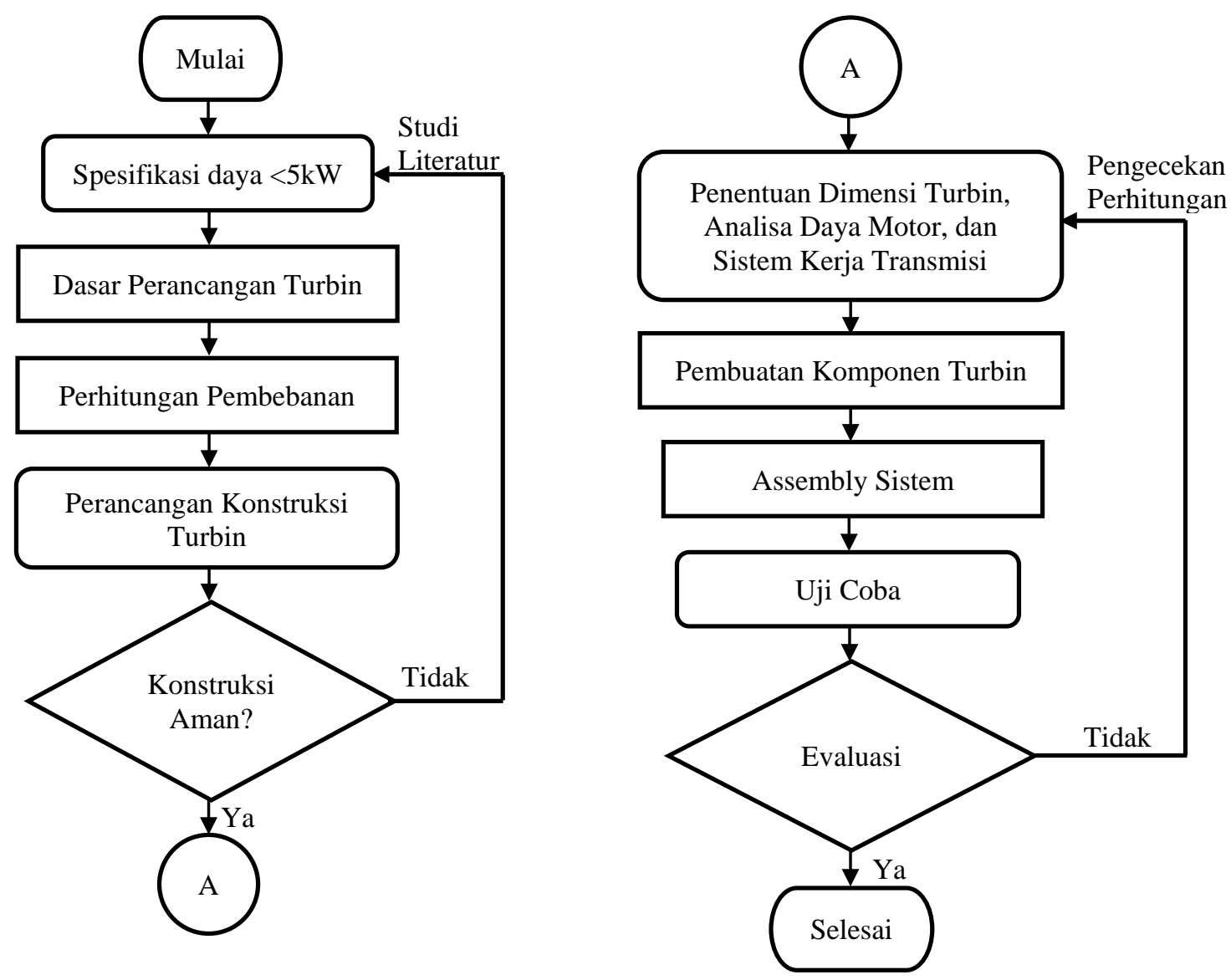

Gambar 1. Diagram alir rancang-bangun mesin turbin air cross-flow

\section{HASIL DAN PEMBAHASAN}

Pada perancangan turbin air ini, diameter luar turbin yang digunakan adalah $150 \mathrm{~mm}=$ $0,150 \mathrm{~m}$. Debit air yang digunakan $(\mathrm{Q})=1,4 \mathrm{~L} / \mathrm{s}$ dengan $\rho$ air $=1000 \mathrm{~kg} / \mathrm{cm}^{3}$ dan asumsi putaran (n) $=1000 \mathrm{r} / \mathrm{min}$. 


\section{Turbin}

1. Tinggi Sudu

$$
\begin{aligned}
\mathrm{a} & =0,17 \cdot D_{1} \\
& =0,17 \cdot 0,150 \\
& =0,0255 \mathrm{~m}
\end{aligned}
$$

2. Diameter dalam Turbin

$$
\begin{aligned}
D_{n} & =0,150 \mathrm{~m}-0,0255 \mathrm{~m} \\
& =0,1245 \mathrm{~m}
\end{aligned}
$$

3. Kecepatan Laju Air

$$
\begin{aligned}
V_{1}=C_{m} & =\mathrm{C} \sqrt{2 g H} \\
& =0,98 \sqrt{2 \cdot 9,8 \cdot 10} \\
& =13,75 \mathrm{~m} / \mathrm{s}
\end{aligned}
$$

4. Daya Yang Dihasilkan Turbin

$$
\begin{aligned}
\mathrm{P} & =\eta \cdot \rho \cdot g \cdot Q \cdot H \\
& =0,87 \cdot 1000 \cdot 9,8 \cdot 10 \cdot 0,0014 \\
& =119 \mathrm{w} \text { atau } 0,119 \mathrm{kw}
\end{aligned}
$$

5. Efisiensi Turbin

$$
\begin{aligned}
e_{\max } & =\frac{1}{2} \cdot C^{2} \cdot(1+\psi) \cos ^{2} \alpha 1 \\
& =\frac{1}{2} \cdot 0,98^{2}(1+0,98) \cos ^{2} 16^{\circ} \\
& =0,4802(1,98) 0,924024048 \\
& =0,87 \cdot 100 \% \\
& =87 \%
\end{aligned}
$$

6. Sudut Turbin

$$
\begin{aligned}
\tan \beta 1 & =2 \tan \alpha 1 \\
\tan \beta 1 & =0,57 \\
\beta 1 & =30^{\circ}
\end{aligned}
$$

7. Jumlah Blade

$$
\begin{aligned}
& \begin{array}{l}
s_{1}=\mathrm{K} D_{1} \\
=(0,087)(6 \text { inch }) \\
=0,52 \text { inch }
\end{array} \\
& \mathrm{t}=\frac{s_{1}}{\sin \beta 1}=\frac{0,52 \text { inch }}{0,5}=1,04 \text { inch } \\
& \text { (jarak antar blade) } \\
& \therefore \text { jadi ada } 15 \text { buah blade atau sudu }
\end{aligned}
$$

\section{Poros}

Diketahui:

$\mathrm{P}=0,119 \mathrm{~kW}$

$\mathrm{n}=1000 \mathrm{rpm}$

$\mathrm{Fc}=1,25$ (faktor koreksi daya)

1. Diameter Poros

$$
\mathrm{Pd}=1,25 \text {. 0,119=0,14875 kW }
$$


$\mathrm{T}=9,74 \cdot 10^{5} \cdot \frac{0,14875}{1000}=144,88 \mathrm{~kg} \cdot \mathrm{mm}$

Aluminium dural 6061, $\sigma \mathrm{B}=\frac{310 M P a}{9,8}=31,63 \mathrm{~kg} / \mathrm{mm}^{2}$

$S F_{1}=6,0$

$S F_{2}=1,25$

$\mathrm{T} \alpha=\frac{31.63}{(6.1,25)}=4,21 \mathrm{~kg} / \mathrm{mm}^{2}$ atau $0,0000421 \mathrm{~N} / \mathrm{m}^{2}$ (tegangan geser)

$\mathrm{Kt}=1,5$ (beban puntir)

Ds $=\left[\frac{5,1}{4,21} \cdot 2,0 \cdot 1,5 \cdot 144,88\right]^{1 / 3}$

$=8,02 \mathrm{~mm}$

$\therefore$ jadi diameter poros yang boleh digunakan adalah minimal 8,02 mm untuk konstruksi aman.

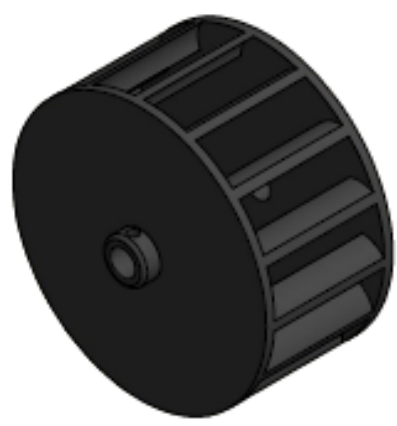

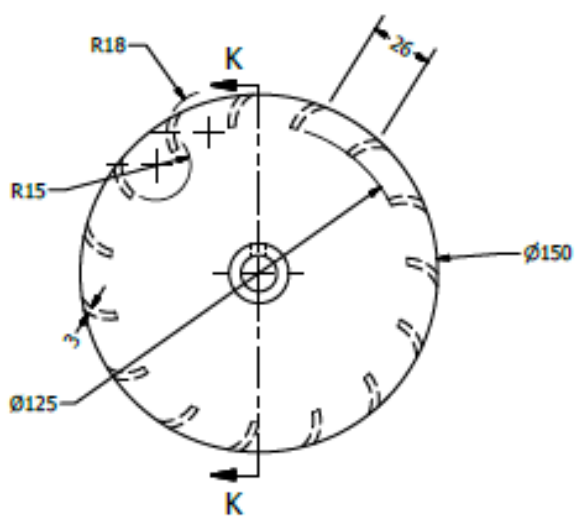

Gambar 3. Dimensi turbin air

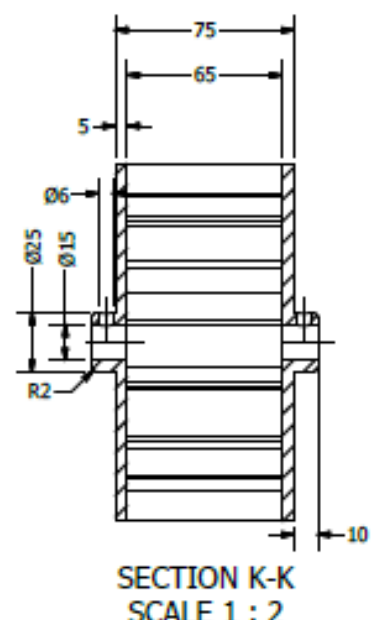

SCALE $1: 2$

2. Perhitungan Poros dengan Pembebanan Vertikal

$\Sigma \mathrm{MB}=0$

$229,32-168 \mathrm{RVA}+84.9,8=0$

$168 \mathrm{RVA}+823,2=0$

$$
\mathrm{RVA}=6,265 \mathrm{~N}
$$

$$
\begin{aligned}
\Sigma \mathrm{MA}=0 & \\
-\mathrm{RVB} .234+150.9,8-66 \mathrm{RVA} & =0 \\
-\mathrm{RVB} .234+1470-413,49 & =0 \\
\mathrm{RVB} & =4,515
\end{aligned}
$$

Cek perhitungan:

$$
\mathrm{F} 1+\mathrm{f} 2=\mathrm{RVA}+\mathrm{RVB}
$$

$0,98+9,8=6,265+4,515$

$$
10,78 \mathrm{~N}=10,78 \mathrm{~N}
$$

\section{Bearing}

Diketahui:

Bearing yang digunakan: single angular contact ball bearing

Putaran (n) = $1000 \mathrm{rpm}$

Asumsi dipakai dua tahun, 24 jam/hari 
Beban radial $(\mathrm{Fr})=15 \mathrm{~N}$ (beban putar)

Beban aksial $(\mathrm{Fa})=15 \mathrm{~N}$ (beban tumpuan)

1. Usia Pakai Bearing

$$
\begin{aligned}
\mathrm{LH} & =(2 \text { tahun } .360) .24 \text { jam } \\
& =17280 \text { jam kerja }
\end{aligned}
$$

2. Beban Dinamis Ekuivalen

$$
\begin{aligned}
& \frac{\mathrm{Fa}}{\mathrm{Fr}}=\frac{15}{15}=1>e(1,14) \\
& \text { Jadi } \mathrm{Xr}=1 \\
& \quad \mathrm{Ya}=0 \rightarrow \text { dari tabel } \\
& \text { V }(\text { faktor rotasi })=1 \\
& \begin{aligned}
\mathrm{Ks} & =1(\text { steady load) } \\
\mathrm{Fe} & =(\mathrm{Xr} . \mathrm{V} \cdot \mathrm{Fr}+\mathrm{Ya} \cdot \mathrm{Fa}) \cdot \mathrm{Ks} \\
& =1.1 \cdot 15+0.15) \cdot 1 \\
& =15 \mathrm{~N} \\
\mathrm{~L} & =30 . \mathrm{n} . \mathrm{LH} \\
& =30.1000 .17280 \\
& =518.10^{6} \text { putaran }
\end{aligned}
\end{aligned}
$$

3. Beban Dinamis

$$
\begin{aligned}
\text { C } & =F e\left(\frac{\mathrm{L}}{10^{6}}\right)^{\frac{1}{\mathrm{k}}} \\
& =15 \mathrm{~N}\left(\frac{518 \cdot 10^{6}}{10^{6}}\right)^{\frac{1}{3}} \\
& =120,146 \mathrm{~N}
\end{aligned}
$$

Jadi bearing nomor 202 aman karena beban dinamis pada bearing nomor 202 yang terdapat pada tabel adalah $6300 \mathrm{~N}$, sedangkan beban dinamis pada hasil perhitungan adalah $120,46 \mathrm{~N}$.

\section{Pulley}

$\mathrm{T}=$ torsi di turbin sampai puli

$=1470 \mathrm{Nmm}$

$F$ = gaya sentrifugal $(\mathrm{N})$

$F=\frac{\mathrm{m} \cdot \mathrm{V}}{\mathrm{r}}$

$F=\frac{1 \mathrm{~kg} \cdot 15,708 \mathrm{~m} / \mathrm{s}}{0,150 \mathrm{~m}}$

$F=104,72 \mathrm{~N}$

$\mathrm{r}=\frac{\mathrm{T}}{\mathrm{F}}=\frac{1470 \mathrm{Nmm}}{104.72 \mathrm{~N}}=14,037 \mathrm{~mm}$

$\mathrm{d}=28 \mathrm{~mm}=2,8 \mathrm{~cm}$ (minimal diameter pulley)

\section{V-belt}

Diketahui:

$\mathrm{n}=1000 \mathrm{rpm}$

$\mathrm{c}=400 \mathrm{~mm}$ (jarak antar poros)

Rasio Transmisi 1:1

$D_{1}=0,11 \mathrm{~m}$ (diameter poros generator)

$D_{2}=0,11 \mathrm{~m}$ (diameter poros turbin pada pulley) 
1. Panjang Sabuk Atau Belt

$$
\begin{aligned}
\mathrm{L} & =2 \mathrm{C}+\frac{\pi}{2}\left(D_{1}+D_{2}\right)+\frac{1}{4 C}\left(D_{1}-D_{2}\right)^{2} \\
& =2.400 \mathrm{~mm}+\frac{\pi}{2}(0,11+0,11)+\frac{1}{4.400}\left(D_{1}-D_{2}\right)^{2} \\
& =800 \mathrm{~mm}+\frac{\pi}{2}(0,22 \mathrm{~m})+\frac{1}{1600 m}(0)^{2} \\
& =800 \mathrm{~mm}+0,34 \mathrm{~m}+\frac{1}{1600 m}(0)^{2} \\
& =1,14 \mathrm{~m}+\frac{1}{1600 m}(0)^{2} \\
& =1140 \mathrm{~mm} \\
& \therefore \text { jadi sabuk } 45 \text { inch didapat dari tabel }
\end{aligned}
$$

2. Kecepatan Sudut

$$
\begin{aligned}
\mathrm{W} & =\frac{\pi \cdot D_{2} \cdot n}{60} \\
& =\frac{\pi \cdot 0,11 \cdot 1000 \mathrm{rpm}}{60} \\
& =5,75 \mathrm{~m} / \mathrm{s}
\end{aligned}
$$

3. Tegangan Efektif di Belt

$$
\begin{aligned}
& P_{0}=\mathrm{Fe} \cdot \frac{w}{102} \\
& 0,119 \mathrm{~kW}=\mathrm{Fe} \cdot \frac{5,72 \mathrm{~m} / \mathrm{s}}{102} \\
& \begin{aligned}
\mathrm{Fe} & =\frac{0,119 \mathrm{kw}}{0,056 \mathrm{~m} / \mathrm{s}} \\
& =2,125 \mathrm{~kg} \\
& =2,125 \cdot 9,8 \mathrm{~m} / \mathrm{s}^{2} \\
& =20,82 \mathrm{~N}
\end{aligned}
\end{aligned}
$$

4. Sudut Kontak

$$
\begin{aligned}
\theta & =180^{\circ}-\frac{(D 2-D 1)}{c} \cdot 57,2^{\circ} \\
& =180^{\circ}-\frac{(0)}{400} \cdot 57,2^{\circ} \\
& =180^{\circ} \\
& =\frac{180^{\circ}}{57,2^{\circ}}=3,146 \mathrm{rad}
\end{aligned}
$$

5. Tensioner Tarik

$$
\begin{aligned}
F_{1} & =\frac{e^{\mu \theta}}{e^{\mu \theta}-1} \cdot \mathrm{Fe} \\
& =\frac{e^{0,3} \cdot 3,146}{e^{0,3 \cdot 3,146-1}} \cdot 20,82 \mathrm{~N} \\
& =\frac{2,569}{1,569} \cdot 20,82 \mathrm{~N} \\
& =34,08 \mathrm{~N}
\end{aligned}
$$

6. Tensioner Regang

$$
\begin{aligned}
\mathrm{Fe} & =F_{1}-F_{2} \\
F_{2} & =F_{1}-\mathrm{Fe} \\
F_{2} & =34,08 \mathrm{~N}-20,82 \mathrm{~N} \\
& =13,26 \mathrm{~N}
\end{aligned}
$$




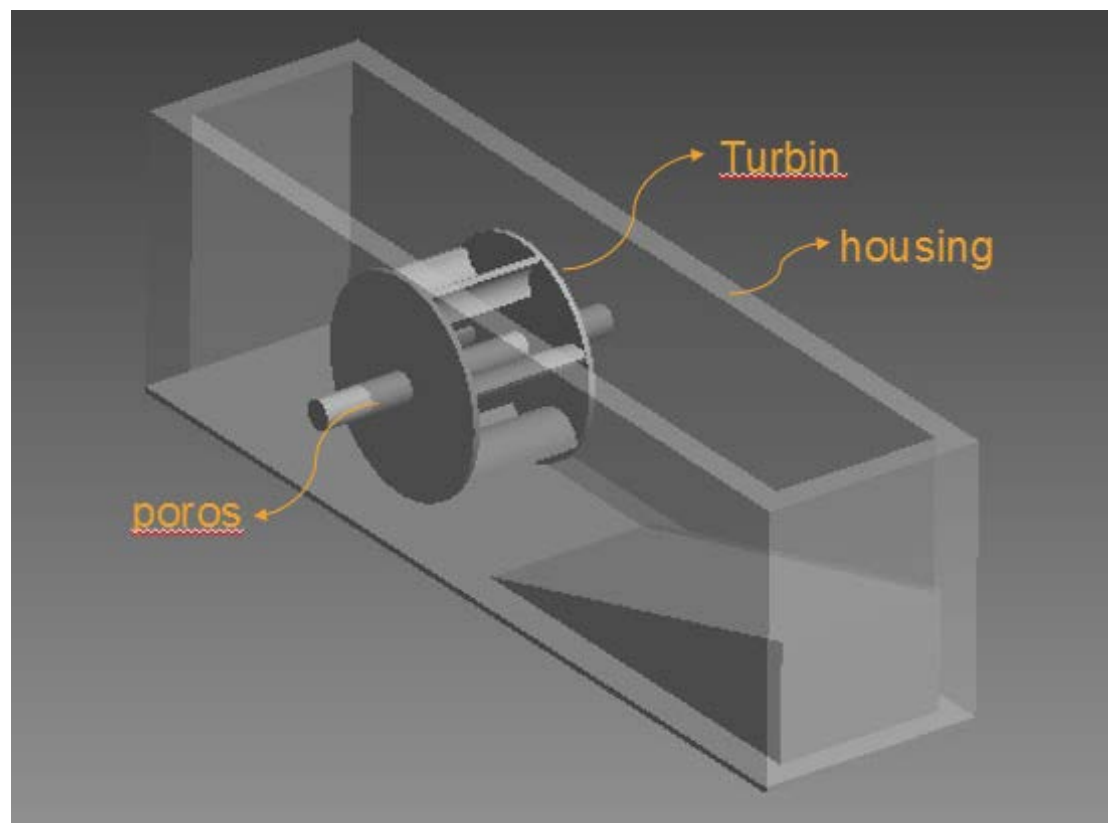

Gambar 2. Model geometri sistem turbin air

\section{SIMPULAN}

Dari perhitungan-perhitungan yang dilakukan untuk rancang bangun hydro turbin jenis cross-flow ini maka diperoleh kesimpulan dari data-data yang dihitung sesuai dengan kegunaannya, sebagai berikut:

\begin{tabular}{|l|c|c|}
\hline Daya yang dibutuhkan & $\mathrm{P}$ & $<5 \mathrm{Kw}$ \\
\hline Daya yang dihasilkan & $\mathrm{P}($ turbin) & $0,119 \mathrm{Kw}$ \\
\hline Diameter poros aman & $\mathrm{d}$ & $\geq 8,02 \mathrm{~mm}$ \\
\hline Diameter poros pakai & $\mathrm{d}$ & $15 \mathrm{~mm}$ \\
\hline Diameter pulley generator (input) & $\mathrm{d}_{\mathrm{i}}$ & $70 \mathrm{~mm}$ \\
\hline Diameter pulley pada turbin (output) & $\mathrm{d}_{0}$ & $70 \mathrm{~mm}$ \\
\hline Panjang belt yang digunakan & $\mathrm{L}$ & $1125 \mathrm{~mm}$ \\
\hline Diameter luar turbin & $D_{1}$ & $150 \mathrm{~mm}$ \\
\hline Diameter dalam turbin & $D_{n}$ & $124,5 \mathrm{~mm}$ \\
\hline Lebar total turbin & $\mathrm{l}$ & $95 \mathrm{~mm}$ \\
\hline Tinggi blade & $\mathrm{a}$ & $25,5 \mathrm{~mm}$ \\
\hline Sudut turbin & $\beta 1$ & $30^{\circ}$ \\
\hline Kecepatan roda yang ideal & $\alpha 1$ & $16^{\circ}$ \\
\hline Jumlah blade turbin & & $15 \mathrm{buah}$ \\
\hline Rasio transmisi & & $1: 1$ \\
\hline Panjang v-belt & & $1125 \mathrm{~mm} / 45$ inch \\
\hline Bantalan No. 202 & & \\
\hline
\end{tabular}

\section{DAFTAR PUSTAKA}

[1] H. Y. S. H. N. M. K. Sallata, PLTMH (Pembangkit Listrik Tenaga Mikro Hidro). Yogyakarta: Penerbit ANDI, 2015.

[2] S. Darmawan et al., "Turbulent flow analysis in auxiliary cross-flow runner of a Proto X-3 Bioenergy micro gas turbine using RNG K- $\varepsilon$ turbulence model," ARPN J. Eng. Appl. Sci., vol. 10, no. 16, 2015. 
[3] V. Sammartano, C. Aricò, A. Carravetta, O. Fecarotta, and T. Tucciarelli, "Banki-Michell optimal design by computational fluid dynamics testing and hydrodynamic analysis," Energies, vol. 6, no. 5, pp. 2362-2385, 2013, doi: 10.3390/en6052362.

[4] R. R. Tito Sahntika, Liman Hartawan, Riduan Sagala, "Perekayasaan Pembangkit Listrik Tenaga Air Untuk Penyediaan Listrik Skala Kecil 100 Watt,” Jurnal Riset Industri, vol. 7, no. 2. pp. 137-146, 2013.

[5] L. A. Haimler, “The Cross-Flow Turbine,” Water Power, vol. 12, no. 1, 1960.

[6] A. A. Nurahman, "Rancang Bangun Runner Turbin Kaplan Untuk Turbin Air Kapasitas Daya 16 kW,” Bandung, 2012.

[7] A. N. Bachtiar, "Perencanaan Turbin Air Penggerak Generator Listrik Pedesaan,” Padang, 1988.

[8] C. A. Mockmore and F. Merryfield, “The Banki Water Turbine,” Bull. Ser., no. 25, 1949, doi: 10.7763/IJMMM.2013.V1.35. 